\title{
Surgical management of cerebellopontine angle arachnoid cysts associated with hearing deficit in pediatric patients
}

\author{
Mario Giordano, MD, ${ }^{1}$ Massimo Gallieni, MD, ${ }^{1}$ Amir Samii, MD, PhD, ${ }^{1,2}$ Concezio Di Rocco, MD, ${ }^{1}$ and \\ Madjid Samii, MD, PhD' \\ 'Department of Neurosurgery, International Neuroscience Institute, Hannover; and 2Leibniz Institute for Neurobiology, \\ Magdeburg, Germany
}

OBJECTIVE Few cases of cerebellopontine angle (CPA) arachnoid cysts in pediatric patients have been described in the literature, and in only 2 of these cases were the patients described as suffering from hearing deficit. In this article, the authors report on 3 pediatric patients with CPA arachnoid cysts ( 2 with hearing loss and 1 with recurrent headaches) who underwent neurosurgical treatment at the authors' institution.

METHODS Four pediatric patients were diagnosed with CPA arachnoid cysts at the International Neuroscience Institute during the period from October 2004 through August 2012, and 3 of these patients underwent surgical treatment. The authors describe the patients' clinical symptoms, the surgical approach, and the results on long-term follow-up.

RESULTS One patient (age 14 years) who presented with headache (without hearing deficit) became asymptomatic after surgical treatment. The other 2 patients who underwent surgical treatment both had hearing loss. One of these children (age 9 years) had recent-onset hypacusia and experienced complete recovery immediately after the surgery. The other (age 6 years) had a longer history (2 years) of progressive hearing loss and showed an interruption of the deficit progression and only mild improvement at the follow-up visit.

CONCLUSIONS CPA arachnoid cysts are uncommon in pediatric patients. The indication and timing of the surgical treatment are fundamental, especially when a hearing deficit is present.

https://thejns.org/doi/abs/10.3171/2017.8.PEDS17341

KEY WORDS cerebellopontine angle; arachnoid cyst; congenital

$\mathrm{A}$ RACHNOID cysts are developmental collections of cerebrospinal fluid (CSF) contained within the arachnoid membrane and subarachnoid space. Their anatomical distribution follows that of the main cerebral cisterns. ${ }^{6}$ These cysts can expand, distort, and compress the surrounding neural structures, eventually producing symptoms..$^{13}$

Aubry and Ombrédanne, in their first report on cerebellopontine angle (CPA) arachnoid cysts, classified these lesions into 3 groups: pseudotumoral, cystic, and adhesive. ${ }^{2}$ With progress in the understanding of arachnoid cysts this classification, which is mostly based on lesion size, has fallen out of use. The first case of a surgically treated CPA arachnoid cyst reported in literature was described by Nichols and Manganiello ${ }^{18}$ in 1953; their patient presented with cerebellar signs and hearing deficit and was treated using a lateral suboccipital approach and opening of the cyst.

Only 15 pediatric cases of CPA arachnoid cysts are presented in the literature. Surprisingly only 2 of the 15 patients were reported to have suffered from hearing deficit. In most of these cases, the clinical presentation included cerebellar signs and/or endocranial hypertension-related symptoms (e.g., headache, nausea, vomiting) (Table 1). Three pediatric patients with CPA arachnoid cysts, 2 with hearing loss and 1 with recurrent headache, who underwent neurosurgical treatment in our institute prompted us to write this report. 
TABLE 1. Review and clinical summary of the patients treated for CPA arachnoid cysts in the literature including our series

\begin{tabular}{|c|c|c|c|c|}
\hline Authors \& Year & Age, Sex & Signs \& Symptoms & Treatment/Operation & Follow-Up \\
\hline Gomez et al., 1968 & 14 yrs, F & $\begin{array}{l}\text { Rt spastic hemiplegia, It spastic } \\
\text { hemiparesis, It dysmetria }\end{array}$ & SOC & Rt hemiplegia improved to hemiparesis \\
\hline Berkmen et al., 1969 & $5 \mathrm{mos}, \mathrm{M}$ & Enlarged head, $\mathrm{HC}$ & VA shunt & $\begin{array}{l}\text { Pt died } 5 \text { mos postoperatively; autopsy } \\
\text { proved cyst }\end{array}$ \\
\hline Little et al., 1973 & $14 \mathrm{yrs}, \mathrm{F}$ & ND & SOC & ND \\
\hline Sumner et al., 1975 & 3 yrs, $F$ & CNs VII \& VIII & Excision & ND \\
\hline Galassi et al., 1985 & $2 \mathrm{yrs}, \mathrm{F}$ & Psychomotor retardation & SOC & $1 \mathrm{yr}:$ normal development \\
\hline Krisht \& O'Brien, 1992 & $1 \mathrm{yr}, \mathrm{F}$ & Vomiting, ataxia & SOC & $\begin{array}{l}2 \text { mos: recurrent vomiting \& irritabil- } \\
\text { ity, contralat cyst found; CP shunt } \\
\text { inserted, pt improved }\end{array}$ \\
\hline Yokota et al., 1993 & $9 \mathrm{yrs}, \mathrm{F}$ & HA, Bruns nystagmus, papilledema & CP shunt & Shunt revision for $\mathrm{HA}$ \\
\hline \multirow[t]{4}{*}{ Jallo et al., 1997} & 14 mos, M & HA, vomiting & Retrosig SOC & Asymptomatic \\
\hline & 3 yrs, M & Ataxia & CP shunt & $\begin{array}{l}\text { Ataxia slightly improved after CP shunt; } \\
\text { however, new CN VII deficit } 3 \text { wks } \\
\text { postop; ataxia \& CN VII deficit re- } \\
\text { solved immed after 2nd op (SOC) }\end{array}$ \\
\hline & 3 yrs, M & $\begin{array}{l}\text { Dysmetria, contralat CN VIII } \\
\text { dysfunction, \& tinnitus }\end{array}$ & Retrosig SOC & $\begin{array}{l}\text { Dysmetria improved; CN VIII dysfunction } \\
\text { \& tinnitus unchanged }\end{array}$ \\
\hline & 3 yrs, F & HA, vomiting & Retrosig SOC & Asymptomatic \\
\hline Boltshauser et al., 2002 & 5 yrs, ND & ND & Fenestration of cyst & ND \\
\hline Ariai et al., 2005 & 7 yrs, M & $\mathrm{HA}$, vomiting, blurred \& dbl vision & Retrosig SOC & Asymptomatic \\
\hline Jayarao et al., 2009 & 12 yrs, F & Hearing loss \& tinnitus & Retrosig SOC & Signif imprvmt \\
\hline Olaya et al., 2011 & 7 yrs, M & Progr hearing loss & Endoscopic fenestration of cyst & Compl resol \\
\hline \multirow[t]{3}{*}{ Present series } & 14 yrs, F & $\mathrm{HA}$ & Retrosig SOC & Asymptomatic \\
\hline & 9 yrs, F & Sensorineural hearing loss & Retrosig SOC & Compl resol, normal hearing function \\
\hline & 6 yrs, M & Sensorineural hearing loss & Retrosig SOC & Mild imprvmt \\
\hline
\end{tabular}

Compl = complete; $\mathrm{CP}=$ cystoperitoneal; $\mathrm{dbl}=$ double; $\mathrm{HA}=$ headache; $\mathrm{HC}=$ hydrocephalus; immed = immediately; imprvmt = improvement; $\mathrm{ND}=$ not described; progr = progressive; $\mathrm{pt}$ = patient; resol = resolution; retrosig = retrosigmoid; signif = significant; $\mathrm{SOC}$ = suboccipital craniotomy; VA = ventriculoatrial.

\section{Methods}

During the period from October 2004 through August 2012, CPA arachnoid cysts were diagnosed in 4 pediatric patients at the International Neurosciences Institute in Hannover, and in 3 of these cases, the cysts were treated surgically. The surgically treated patients were 2 girls and 1 boy, aged, respectively, 9, 14, and 6 years. The arachnoid cysts were located in the right CPA in all cases. The fourth case involved an 11-year-old boy who underwent removal of a left temporal low-grade glioma and was found to harbor an asymptomatic right CPA arachnoid cyst. This patient has been followed for 10 years without any change in the size of the cyst, which has remained clinically silent.

\section{Signs and Symptoms}

The first surgically treated patient was a 14-year-old boy who suffered from recurrent headaches for 5 months before the diagnosis. The other 2 surgically treated patients had cerebellar signs with progressive hearing loss. In one of these patients, the 9-year-old girl, the CPA arachnoid cyst was detected only 2 weeks after the onset of the deficit, with consequent direct treatment. In contrast, the other patient with hearing loss, a 6-year-old boy, was only referred to our institute 2 years after the beginning of the hearing deficit due to delayed diagnosis.

\section{Radiological Findings}

All patients underwent MRI with T1- and T2-weighted, fluid attenuated inversion recovery (FLAIR), and diffusion-weighted sequences. All the cysts appeared as welldefined, nonenhancing lesions isointense to CSF. Highresolution sequences, such as constructive interference in steady state (CISS), helped the precise delineation of cyst wall and adjacent neural and vascular structures. There was no preoperative diagnosis of hydrocephalus. The mean sizes of the lesions in the craniocaudal, lateromedial, and anteroposterior dimensions were $11.8 \mathrm{~mm}, 16.8$ $\mathrm{mm}$, and $13.6 \mathrm{~mm}$, respectively.

\section{Surgery}

In all 3 cases, surgery was performed via a retrosigmoid craniotomy with the patient in a semisitting position, after a screening to exclude patent foramen ovale. The dura was incised in a C-shaped fashion. To minimize cerebellar retraction, the lateral cerebellomedullary cistern 


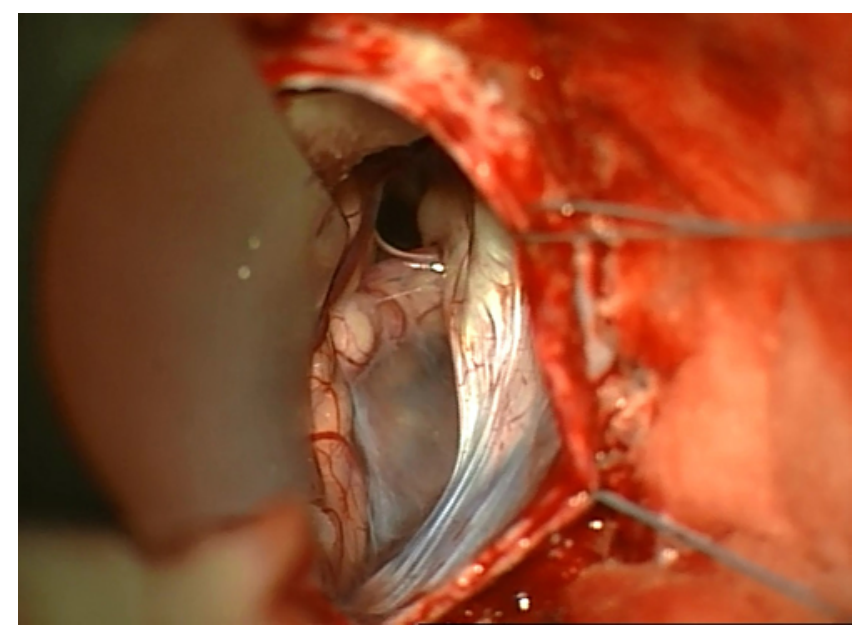

FIG. 1. Intraoperative image obtained in a child with a CPA arachnoid cyst. After dura opening and gentle cerebellar retraction, the posterior wall of the cyst formed by thickened arachnoid is visualized. Figure is available in color online only.

was opened for CSF drainage. After gentle retraction, the posterior wall of the arachnoid cyst was visualized (Fig. 1) and opened. After aspiration of the fluid, the cyst wall was carefully dissected from the surrounding vascular and neural structures in order to obtain extensive removal (Fig. 2). The area caudal and cranial to the seventh and eighth cranial nerve (CN VII-VIII) complex was carefully explored and further intracystic septations were opened and removed, providing a wide communication with the subarachnoid cisterns.

Jugular venous compression was always performed before dura closure to detect any damaged vein that could cause postoperative bleeding. Opened mastoid air cells were carefully occluded with fragments of fat harvested subcutaneously and sealed with fibrin glue. During the entire procedure brainstem auditory evoked potentials were measured to monitor acoustic nerve function and electromyography recordings of the orbicularis oris and oculi muscles were used to monitor facial nerve function.

\section{Results}

There were no deaths in this surgical series. The patient with headaches became asymptomatic and remained so throughout the subsequent 12 years of follow-up. The patient with the recent onset of hypacusia experienced complete recovery immediately after the surgery and has remained asymptomatic throughout 13 years of follow-up. The second patient with hearing deficit, who had a longer history (2 years) of progressive hearing loss before the surgical treatment, showed an interruption of the deficit progression and only mild improvement over 5 years of follow-up.

Despite the different postoperative evolution of the symptoms, the follow-up imaging studies performed 6 months after surgery showed a reexpansion of the previously compressed cerebellum (Fig. 3) in all 3 patients with surgically treated CPA arachnoid cysts. At the 1-year follow-up evaluation, MRI demonstrated symmetry of the

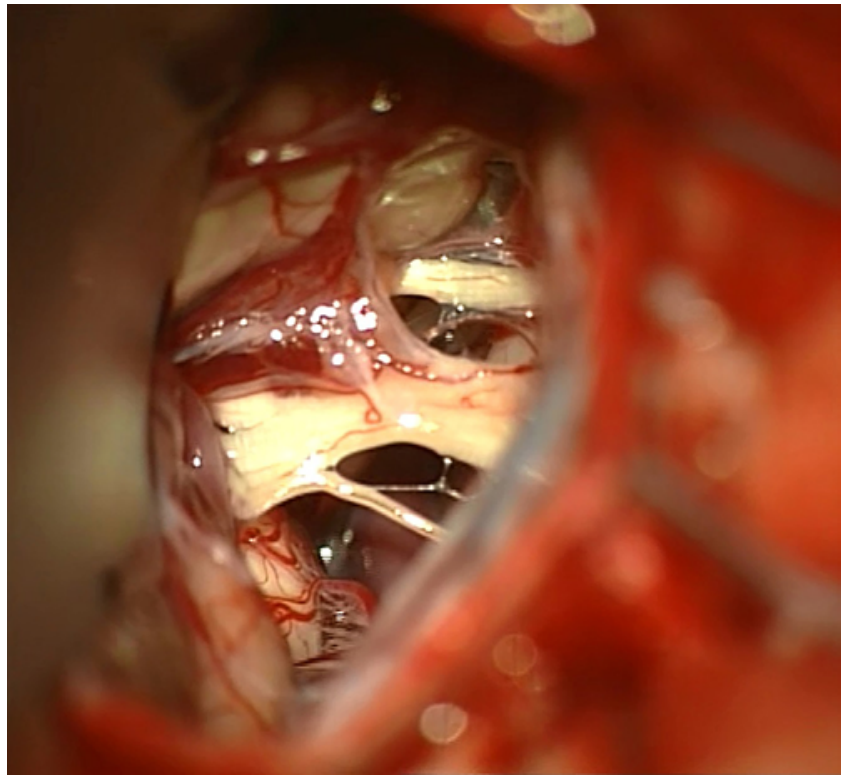

FIG. 2. Intraoperative image obtained in the same case as Fig. 1 after opening of the cyst and extensive removal of the cyst wall. The abducens nerve and the CN VII-VIII complex are entirely dissected and decompressed. Figure is available in color online only.

CPA cisterns bilaterally in all 3 patients with no signs of recurrence.

\section{Discussion}

There are few reports in the English literature regarding surgical treatment of CPA arachnoid cysts in children. Including the 3 patients described here, 18 cases have been reported as either individual case reports or as a subgroup in a series of infratentorial arachnoid cysts (Table 1). ${ }^{1,3,4}$, $8,11,13,14,16,17,19,21,22$

The indications for surgery and the type of surgical treatment are still subjects of debate..$^{13}$ Not all arachnoid cysts require surgical intervention. Conservative management with regular radiological control for asymptomatic patients will identify those patients with gradual cyst enlargement and/or manifestation of new symptoms that could need surgical treatment. ${ }^{20}$ Consequently, in case of
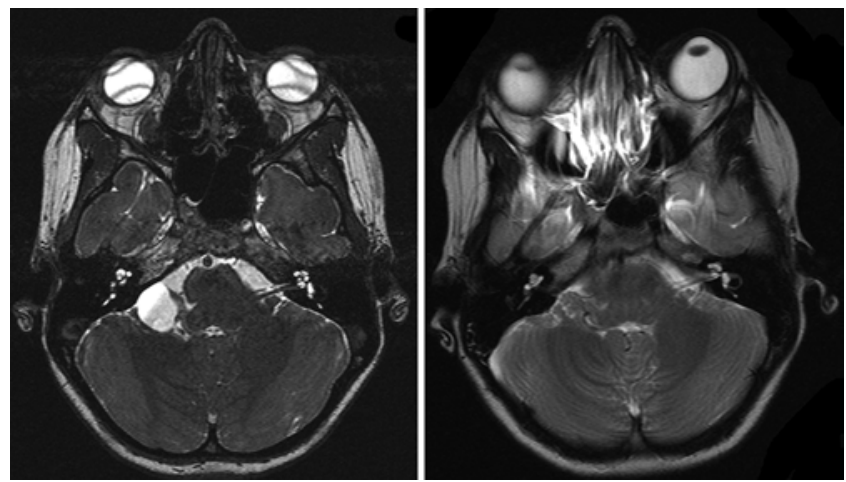

FIG. 3. Preoperative (left) and postoperative (right) T2-weighted MR images showing the right CPA arachnoid cyst (left) and the complete reexpansion of the cerebellum 6 months after surgery (right). 
incidental discovery of a CPA arachnoid cyst in an asymptomatic individual, a "wait-and-see" strategy could be justified, but the patient's family should be aware that any initial loss of hearing or evidence of cyst enlargement at neuroimaging should prompt immediate consideration of the possibility of surgical treatment, as long-standing acoustic deficits seem to not respond or respond only partially to the cyst excision. In fact, in patients with a long history of hearing loss, the family should be informed about the possibility that surgery may not restore normal acoustic function.

Indications for operative management include the presence of cyst growth, signs of neural compression, or hydrocephalus. ${ }^{13}$

Different surgical techniques have been reported for the treatment of intracranial arachnoid cysts: microscopic approach with cyst fenestration, marsupialization into the subarachnoid space and/or resection of the cyst wall, stereotactic puncture, and cystoperitoneal shunt placement or treatment of the associated hydrocephalus. Endoscopic management is becoming used more often. For the CPA arachnoid cyst in particular, direct attack of the cyst through a lateral suboccipital approach was predominant (Table 1). ${ }^{5,20}$ Aspiration techniques using stereotactic or endoscopic puncture ${ }^{9,10}$ are described in some reports, although reclosure of the cyst wall ${ }^{7}$ or insufficient fenestration resulting in inadequate drainage into the subarachnoid space are complications, leading to recurrence and regrowth. Cystoperitoneal shunting, as advocated by Ciricillo et al. ${ }^{5}$ also carries a risk of recurrence due to the occlusion of the system. ${ }^{12,15}$ Moreover, because of the close relationship to many important neurovascular structures in this area, cyst shunting, puncture, or endoscopic procedures may be hazardous in these patients.

Encouraging results in treatment and avoidance of recurrence have been observed in our previous experience with adult patients using a microsurgical retrosigmoid approach with resection of the cyst wall. ${ }^{20}$

Hearing loss is a rare presenting symptom of patients with CPA arachnoid cysts, described only in 2 previous pediatric cases reported in the literature. ${ }^{14,19}$ Although the exact pathophysiological mechanism for hearing loss in patients with arachnoid cysts has not been well described, various hypotheses have been proposed. Jayarao et al. ${ }^{14}$ suggested that their patient was symptomatic as a result of the arachnoid cyst exerting mass effect on the $\mathrm{CN}$ VII-VIII complex. It has been suggested that long-term compression of the cranial nerves in the CPA may cause irreversible nerve damage, most likely due to vascular injury. Even though it is often stated that children could have a better chance of recovery than adults because of the plasticity of the child's nervous system, the duration of the clinical history in symptomatic cases appears to be significant. Indeed, by analyzing the cases presented in the literature $\mathrm{r}^{14,19}$ and taking into account our own experience, we noticed that the patients with a longer preoperative duration of deficit had a worse hearing outcome (Table 2).

Also, considering all the cases presented in the literature, we can observe different outcomes: 1) complete resolution of the hearing deficit, as in the 2 children (one described by Olaya et al. ${ }^{19}$ and one in the present series)
TABLE 2. Cases of CPA arachnoid cysts in which patients presented with hearing deficits

\begin{tabular}{lccc}
\hline & Time to & \multicolumn{2}{c}{ Outcome } \\
\cline { 3 - 4 } Authors \& Year & Treatment & Immed Postop & Long-Term FU \\
\hline Jayarao et al., 2009 & 14 mos* $^{*}$ & Unchanged & Signif imprvmt \\
\hline Olaya et al., 2011 & 6 mos & Compl resol & $\begin{array}{c}\text { Normal hear- } \\
\text { ing function }\end{array}$ \\
\hline Present Case 1 & 3 wks & Compl resol & $\begin{array}{r}\text { Normal hear- } \\
\text { ing function }\end{array}$ \\
\hline Present Case 2 & 24 mos & Unchanged & Mild imprvmt \\
\hline $\begin{array}{l}\text { FU = follow-up. } \\
\text { * Not precisely stated in the publication. }\end{array}$ & &
\end{tabular}

operated on shortly after diagnosis, who demonstrated immediate postoperative improvement of hearing deficit; 2) significant improvement, as in the patient described by Jayarao et al., ${ }^{14}$ who showed improved hearing at the 3 -year follow-up visit but not in the immediate postoperative evaluation; and 3) only mild improvement, as in the child who was referred to our institute and treated 2 years after onset of hearing deficit, due to delayed diagnosis.

\section{Conclusions}

Cerebellopontine angle arachnoid cysts are uncommon in the pediatric population. The indications for treatment are of paramount importance in cases of symptom progression. If a hearing deficit is present, rapid surgical treatment is recommended to increase the chances of recovery.

\section{References}

1. Ariai S, Koerbel A, Bornemann A, Morgala M, Tatagiba M: Cerebellopontine angle arachnoid cyst harbouring ectopic neuroglia. Pediatr Neurosurg 41:220-223, 2005

2. Aubry M, Ombrédanne M: Étude oto-neurologique et chirurgicale du vertige. Paris: Masson, 1937

3. Berkmen YM, Brucher J, Salmon JH: Congenital arachnoid cysts. Am J Roentgenol Radium Ther Nucl Med 105:298304, 1969

4. Boltshauser E, Martin F, Altermatt S: Outcome in children with space-occupying posterior fossa arachnoid cysts. Neuropediatrics 33:118-121, 2002

5. Ciricillo SF, Cogen PH, Harsh GR, Edwards MS: Intracranial arachnoid cysts in children. A comparison of the effects of fenestration and shunting. J Neurosurg 74:230-235, 1991

6. di Rocco C: Arachnoid cysts, in Youmans JR (ed): Neurologic Surgery, ed 3. Philadelphia: Saunders, 1990

7. di Rocco C, Caldarelli M, di Trapani G: Infratentorial arachnoid cysts in children. Childs Brain 8:119-133, 1981

8. Galassi E, Tognetti F, Frank F, Fagioli L, Nasi MT, Gaist G: Infratentorial arachnoid cysts. J Neurosurg 63:210-217, 1985

9. Gangemi M, Maiuri F, Colella G, Sardo L: Endoscopic surgery for large posterior fossa arachnoid cysts. Minim Invasive Neurosurg 44:21-24, 2001

10. Godano U, Mascari C, Consales A, Calbucci F: Endoscopecontrolled microneurosurgery for the treatment of intracranial fluid cysts. Childs Nerv Syst 20:839-841, 2004

11. Gomez MR, Yanagihara T, MacCarty CS: Arachnoid cyst of the cerebellopontine angle and infantile spastic hemiplegia. Case report. J Neurosurg 29:87-90, 1968 
12. Harsh GR IV, Edwards MS, Wilson CB: Intracranial arachnoid cysts in children. J Neurosurg 64:835-842, 1986

13. Jallo GI, Woo HH, Meshki C, Epstein FJ, Wisoff JH: Arachnoid cysts of the cerebellopontine angle: diagnosis and surgery. Neurosurgery 40:31-38, 1997

14. Jayarao M, Devaiah AK, Chin LS: Recovery of sensorineural hearing loss following operative management of a posterior fossa arachnoid cyst. Case report. J Neurosurg Pediatr 4:121-124, 2009

15. Kaplan BJ, Mickle JP, Parkhurst R: Cystoperitoneal shunting for congenital arachnoid cysts. Childs Brain 11:304-311, 1984

16. Krisht AF, O’Brien MS: Acquired mirror-image cerebellopontine angle arachnoid cysts: case report. Neurosurgery 30:798-800, 1992

17. Little JR, Gomez MR, MacCarty CS: Infratentorial arachnoid cysts. J Neurosurg 39:380-386, 1973

18. Nichols P Jr, Manganiello LO: Traumatic arachnoidal cyst simulating acoustic neurinoma. J Neurosurg 10:538-539, 1953

19. Olaya JE, Ghostine M, Rowe M, Zouros A: Endoscopic fenestration of a cerebellopontine angle arachnoid cyst resulting in complete recovery from sensorineural hearing loss and facial nerve palsy. J Neurosurg Pediatr 7:157-160, 2011

20. Samii M, Carvalho GA, Schuhmann MU, Matthies C: Arachnoid cysts of the posterior fossa. Surg Neurol 51:376382,1999
21. Sumner TE, Benton C, Marshak G: Arachnoid cyst of the internal auditory canal producing facial paralysis in a threeyear-old child. Radiology 114:425-426, 1975

22. Yokota J, Imai H, Okuda O, Sato K: Inverted Bruns' nystagmus in arachnoid cysts of the cerebellopontine angle. Eur Neurol 33:62-64, 1993

\section{Disclosures}

The authors report no conflict of interest concerning the materials or methods used in this study or the findings specified in this paper.

\section{Author Contributions}

Conception and design: Giordano, Gallieni, Di Rocco. Acquisition of data: Gallieni, M Samii. Analysis and interpretation of data: Giordano. Drafting the article: Giordano, Gallieni. Critically revising the article: Giordano, A Samii, Di Rocco, M Samii. Administrative/technical/material support: Giordano, M Samii. Study supervision: A Samii, Di Rocco, M Samii.

\section{Correspondence}

Mario Giordano, International Neuroscience Institute-Hannover, Rudolf Pichlmayr Str. 4, Hannover 30625, Germany. email: giordano.nch@gmail.com. 